\title{
The Comparison of Compact (COM 4) Yarns with Conventional Ring Yarns
}

\author{
Suat CANOĞLU \\ Marmara University, Faculty of Technology, Department of Textile Engineering, Istanbul, Turkey
}

\begin{abstract}
In this study, flax fabrics were applied with oxygen and nitrogen plasma treatment for different execution time. After the plasma treatment, the effects of gas type and execution time on flax fabrics were investigated in terms of shear strength, hydrophility, color differences, dimensional change and surface properties. According to the results, nitrogen plasma treatment caused to increase the shear strength of flax fabrics more than oxygen plasma treatment. Furthermore, the oxygen and nitrogen plasma treatment caused to increase of hydrophility of flax fabrics and the hydrophility of samples increased with the increment in execution time of plasma treatment. The color differences results indicated that there were not significant differences in color change of flax samples. Besides, scanning electron microscope images demonstrated that the nitrogen plasma treatment provided the optimal surface modification. According to the results, plasma treatment can be improved the physical and chemical properties of flax fabrics.
\end{abstract}

Keywords: Flax, Plasma Treatment, Shear Strength, Hydrophility, Color Differences, Dimensional Change.

\section{INTRODUCTION}

Compact spinning system is a modified ring spinning technology. The yarn properties produced in this system, especially the hairiness and tensile properties of the yarns, are much better than the conventional ring spun yarns [1-4]. This was appeared by minimizing the spinning triangle in ring spinning machine. This is the most critical part of the ring spinning system. In this zone, the fibre assembly doesn't have any twist [5]. Fibres, which have left the main drafting unit are later condensed by the aerodynamic forces and has performed the compact and perfect yarn formation. Yarn hairiness is the most important property, which provides this perfect structure. As it is known, hairiness is one of the important parameters for spinners and for further processors in textiles; due to the hairiness in the yarn some defaults on the fabric may later be appeared. Warp drawer-in and warp yarn tangling during weaving process and hence warp yarn breakages, pilling on the knitted and woven fabrics and some defaults on the appearance of fabrics can be given as an example $[6,7]$. These negative characteristics have been mostly eliminated in compact yarns.

\section{COMPACT SPINNING IN SHORT STAPLE YARN PROCESS}

Up to date, no other new spinning system than that of ring spun yarn has presented a quality and a flexible yarn. A clear example is that the ring spinning system has the ability for producing finer counts. However ring spun yarns have very little protruding fibres that affect the yarn tenacity and these fibres have a negative effect on the hairiness and on the irregularity. The ComforSpin process for the ring spinning system has mostly eliminated this negativeness. These yarns are called COM 4. Figure 1 shows the standard ring spun yarn and COM 4 yarn, Figure 2 compares the produced fabrics of these yarns [8,9] and Figure 3 (a-b) shows compacting zone of the compact system.

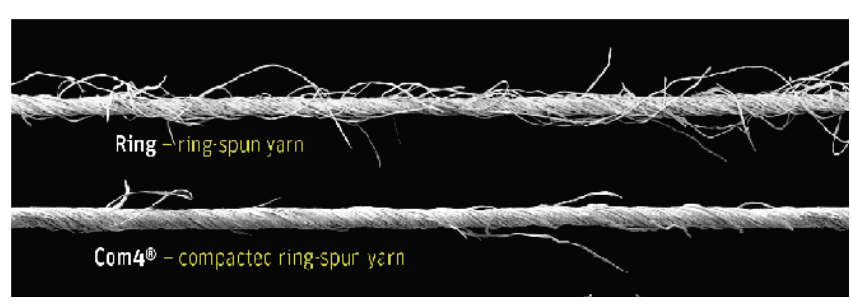

Figure 1. Structure of ring spun and COM 4 yarns

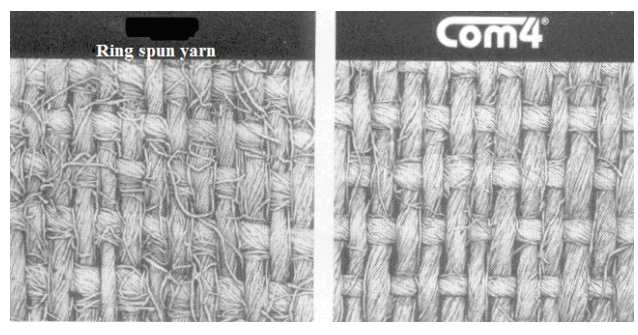

Figure 2. Fabrics made of ring spun and COM 4 yarns

Corresponding Author: Suat CANOĞLU, Tel: +90 21641405 45, E-mail: scanoglu@marmara.edu.tr Submitted: 15 October 2014, Revised: 04 March 2015, Accepted: 01 July 2015 


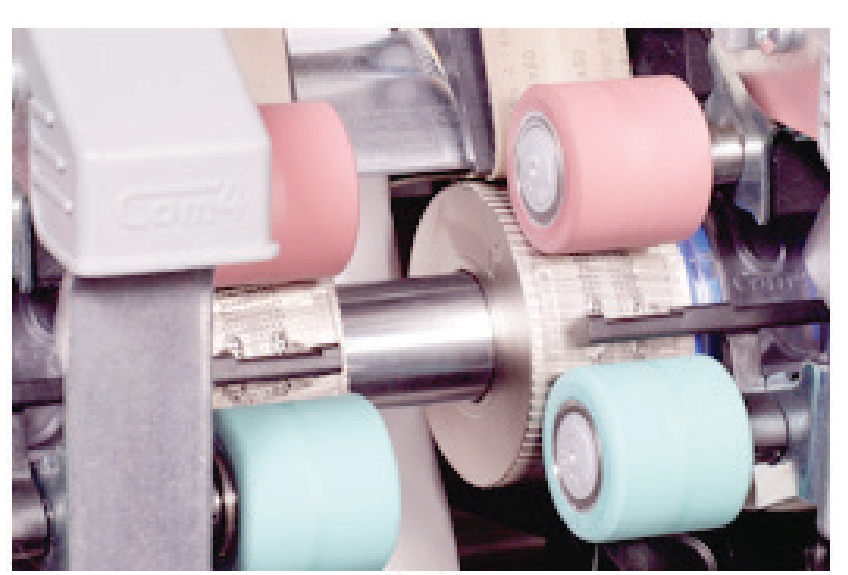

(a)
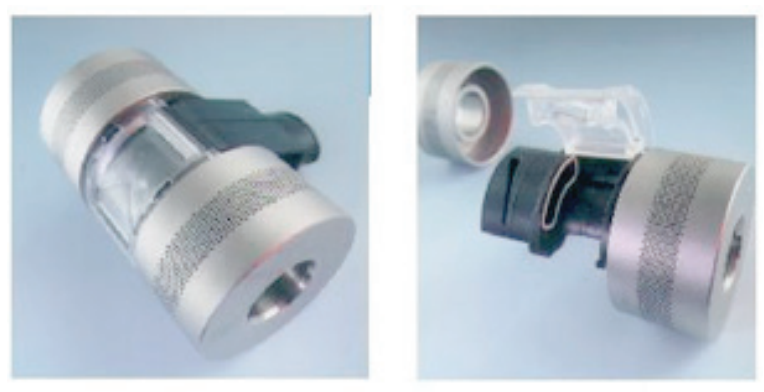

(b)

Figure 3. K44 compacting unit

\section{MATERIALS AND METHOD}

In this study, 20 tex combed cotton weaving yarns were produced with the twist factor atex 35.3 All the yarns were tested in the standard atmosphere conditions $(20 \pm 2 \mathrm{C} 0$ and $\% 65 \pm 2 \mathrm{RH})$ after 48 hours of equilibrium was reached. The fibre parameters and ring machine details are given in Table 1 and in Table 2.

Table 1. Fibre parameters

\begin{tabular}{|c|c|}
\hline \multirow[t]{2}{*}{ Measured fibre parameters } & Fibre used in the study \\
\hline & Cotton \\
\hline Fibre fineness (micronaire) & 4.3 \\
\hline Fibre length (mm) & 30.7 \\
\hline Fibre strength (g/tex) & 32.4 \\
\hline Fibre elongation (\%) & 6.6 \\
\hline Uniformity (\%) & 85.6 \\
\hline
\end{tabular}

Table 2. Ring machine specifications

\begin{tabular}{cc}
$\begin{array}{c}\text { Technological/machine set } \\
\text { parameters } \\
\text { Ring yarn type }\end{array}$ & Dimensions \\
Spindle speed (rev/min) & Conventional/Compact \\
Ring diameter (mm) & 18000 \\
Traveller type (ISO No) & 40 \\
Type of traveller & 35.5 \\
Theoretical twist coefficient & C1 EL udr orbit \\
$\left(\alpha_{\text {tex }}\right)$ & 35.3 \\
Theoretical twist (turns) & 904 \\
\hline
\end{tabular}

\section{RESULTS}

\subsection{Yarn Linear Density, Twist Parameters, Yarn Breaking Tenacity and Elongation}

In this study, two different types of yarns (compact and conventional ring yarns) were produced at the same yarn linear densities and these were abbreviated as A and B in the tables. The linear densities, twist parameters and yarn breaking tenacity with elongation are tabulated in table 3. Breaking tenacity and elongation of the yarns were determined according to ASTM D5035-95 standard by using Uster Tensorapid instrument. All tests were carried out in the standard atmosphere conditions ( $(20 \pm 2 \mathrm{C} 0$ and $\%$ $65 \pm 2 \mathrm{RH})$ after 48 hours of equilibrium was reached.

Table 3. Yarn linear density and twist parameters

\begin{tabular}{cccccc}
\hline $\begin{array}{c}\text { Ring yarn } \\
\text { type }\end{array}$ & $\begin{array}{c}\text { Abbrevia- } \\
\text { tions }\end{array}$ & $\begin{array}{c}\text { Measured } \\
\text { yarn linear } \\
\text { density (tex) }\end{array}$ & $\begin{array}{c}\text { Measured } \\
\text { yarn twist }\end{array}$ & $\begin{array}{c}\text { Measured } \\
\text { breaking } \\
\text { strength } \\
\text { (turns/m) }\end{array}$ & $\begin{array}{c}\text { Measured } \\
\text { elongation }\end{array}$ \\
$\begin{array}{c}\text { Compact } \\
\text { (COM 4) }\end{array}$ & A & 19.75 & 904 & 18.3 & 5.5 \\
$\begin{array}{c}\text { Conven- } \\
\text { tional ring } \\
\text { spun yarn }\end{array}$ & B & 19.81 & 899 & 16.3 & 5.0 \\
& & & & & \\
& & & & &
\end{tabular}

\subsection{Yarn Imperfections and Hairiness}

Yarn imperfections and hairiness were tested on the USTER TESTER 4-SX R1.8. All samples run through the tester at $400 \mathrm{~m} / \mathrm{min}$. The imperfections are listed in Table 4. 
Tablo 4. Yarn imperfections

\begin{tabular}{|c|c|c|c|c|c|}
\hline $\begin{array}{c}\text { Yarn } \\
\text { abbreviations }\end{array}$ & $\begin{array}{c}\text { Mean } \\
\text { linear } \\
\text { irregularity, } \\
(\text { Um) }\end{array}$ & $\begin{array}{c}\text { Thin } \\
\text { places, } \\
(1 / \mathrm{km})\end{array}$ & $\begin{array}{c}\text { Thick } \\
\text { places, } \\
(1 / \mathrm{km})\end{array}$ & $\begin{array}{c}\text { Neps, } \\
(1 / \mathrm{km} \\
)\end{array}$ & $\begin{array}{c}\text { Hairiness, } \\
(\mathrm{H})\end{array}$ \\
\hline $\mathrm{A}$ & 9.2 & 0 & 17 & 23 & 4.0 \\
$\mathrm{~B}$ & 9.7 & 1 & 16 & 17 & 5.3 \\
\hline
\end{tabular}

\subsection{Fabrics Production and Pilling}

Knitted samples were produced for each yarn type, on the socks machine of Bentley Comet $\mathrm{CP}$ of 4-inch diameter with 168 needless, to be able to see how hairiness was reflected on the fabrics. The samples were conditioned under the standard atmosphere for 48 hours and five samples from the knitted fabrics have been tested for their pilling on the $\mathrm{Nu}$ Martindale Abrasion Tester. Testing period was set 1000 rubs and later the samples were compared with the K3 Empa standard photographs [SN. 1985-25] for their pilling. Pilling values of the fabrics are classified from worse to best as 1-3, $2-3,3-4$ and 4-5. Thus the pilling test results of the samples were given in Table 5 .

Table 5. Pilling data of the knitted fabrics

\begin{tabular}{cc}
\hline Yarn Abbreviations & Pilling \\
A & $3-4$ \\
B & $1-2$ \\
\hline
\end{tabular}

\section{CONCLUSIONS}

The overall results are presented at the following conclusions:

- Table 3 shows that compact (COM 4 - Rieter K44) yarns have higher twist than the conventional ring spun yarns (Rieter G30).

- Table 3 demonstrates that COM 4 yarns have higher breaking strength than that of conventional ring spun yarns.

- Tablo 3 also presents that COM 4 yarns have higher elongation than that of ring spun yarns.

- Mean linear irregularity of the COM 4 yarn is better than that of standard ring spun yarn.
- Hairiness (Uster H) values of the COM 4 yarns are lover than that of standard conventional ring spun yarns.

- Regarding to the Table 5, yarn hairiness directly revealed on the fabrics; knitted Compact (COM 4) yarns show better than that of produced standard conventional ring spun yarns.

\section{REFERENCES}

[1] Kampen, W., The Advantages of Condensed Spinning, Melliand English, 2000, No.4, p.58-59.

[2] Cheng, K.P.S. Yu, C., A Study of Compact Spun Yarns, Textile Research Journal 2003, No.4, p.345349.

[3] Beceren, Y., Nergis, B., U., Comparison of the Effects Cotton Yarns Produced by New, Modified and Conventional Spinning Systems on Yarn and Knitted Fabric Performance, Textile Research Journal 2008, 78(4), p.297-303.

[4] S. Genesan, A. Venkatachalam, V. Subramaniam, Fiber Migration in Compact SpunYarns : Part II- Mechanical Compact Yarn, Indian Journal of Fiber \&Textile Research, 2007, 32,p. 169-172

[5] S. Ömeroğlu, and S. Üllkü, An Investigation about Tensile Strength, Pilling and Abrasion Properties of Woven Fabrics Made from Conventional and Compact Ring-Spun Yarns, Fibers \& Textiles in Eastern Europe, 2007, 15(1), p.39-42.

[6] Hattenschwiller, P., Yarn Hairiness: Thoughts and Examples, Melliand Textilberichte, 1989, p. 59-67.

[7] Brown, P., A Preliminary Study of The Fiber Length Distribution in Fly Produced During the Weft Knitting of Cotton Yarns, Textile Research Journal 1978, 48(3), p.162.

[8] https://www.google.com.tr/?gfe_rd=cr\&ei=4WshVIia GemI8Qf6rQE\&gws_rd=ssl\#q=rieter+com $+4+$ yarn $+\mathrm{a}$ nd+conventional+ring + yarn + picture

[9] Rieter 2000 Türkiye Symposium Proceeding, p: 26-30 